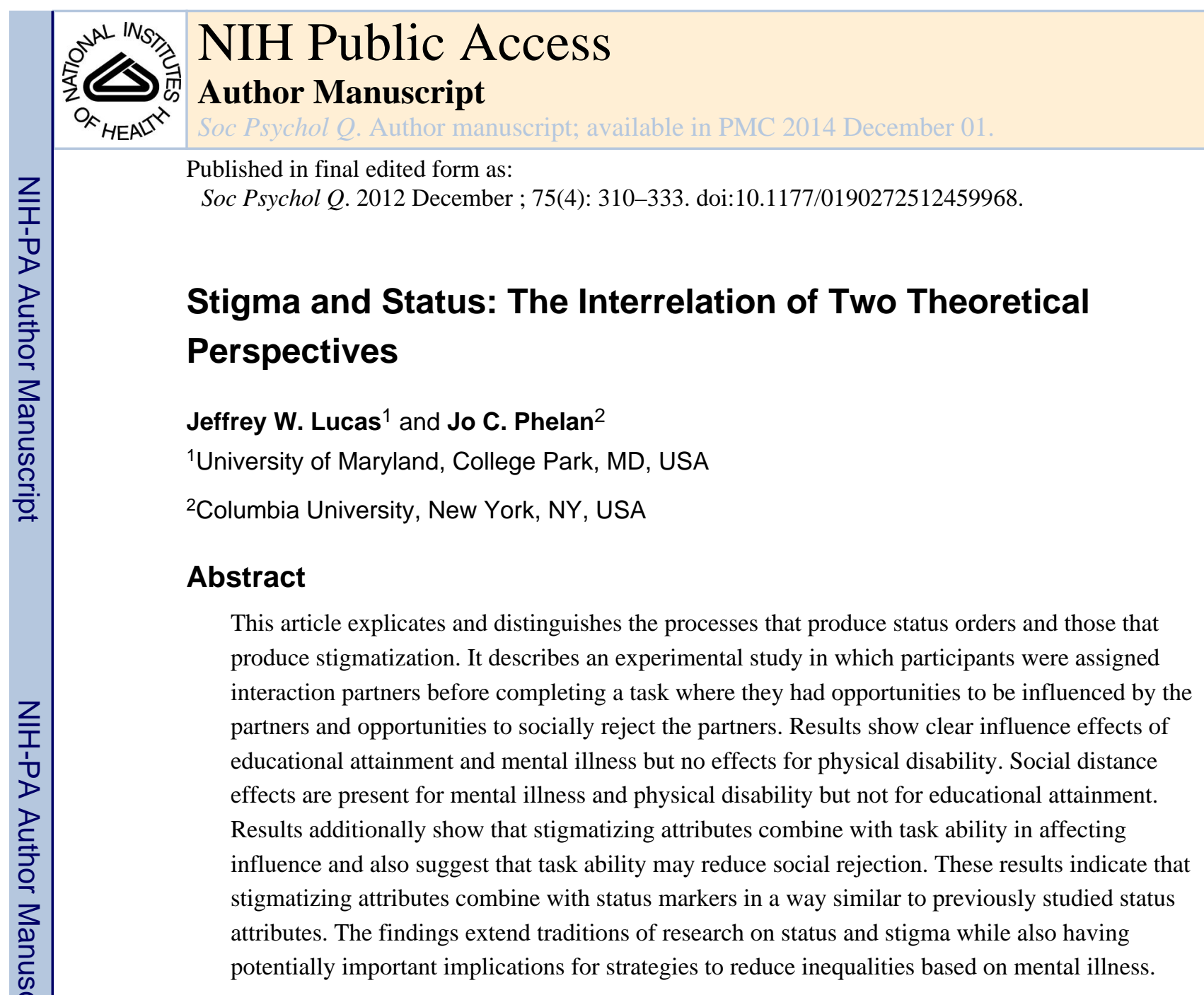

\title{
Keywords
}

status processes; stigma; mental illness; physical disability

Stigma and status are the major concepts in two important traditions of theory and research in sociology that describe related processes. Both traditions focus on how the characteristics of individuals produce unequal outcomes in interpersonal interactions and both attend to the power of expectations in producing those unequal outcomes. The literatures differ, however, in the outcomes to which they attend and the characteristics on which they focus, and the two traditions have developed independently without the benefit of theoretical or empirical enrichment, challenge, refinement, or enlargement from each other.

Work in both the status and stigma traditions stands to benefit substantially if we can identify points of departure and integration between the programs as well as draw from each program's strengths to inform the other. We see the benefits of such an enterprise as threefold. First, by examining how the social processes described in these two literatures are distinct, our theoretical understanding of interpersonal processes that lead to unequal

(C) American Sociological Association 2012

Corresponding Author: Jeffrey W. Lucas, Department of Sociology, University of Maryland, 2112 Art-Sociology, College Park, MD 20742-1315, USA, jlucas2@umd.edu. 
outcomes will be improved and refined. Second, to any extent that the two approaches appear to address substantially similar processes, the large empirical literatures of each tradition will become relevant and useful to the other. Third, to the extent that the processes overlap, interventions aimed at reducing unequal outcomes may be adopted across the two areas.

The status and stigma literatures describe basic social processes that emerge during interpersonal interactions. They are basic processes in that the characteristics that produce them vary by time and place, but the processes themselves exist as fundamental organizing features of social groups. Theory and research on status as a basic social process focus on hierarchies of influence and prestige. This work in general has attended to the mechanisms that lead from the characteristics of members to influence and evaluation differences in task groups. Link and Phelan (2001) describe stigma as involving the co-occurrence of components of labeling, stereotyping, cognitive separation into "us" and "them" groups, status loss, social rejection, and discrimination, in the context of power differentials that allow one group to successfully devalue another. The dimensions of status loss and discrimination can be seen, at least in broad strokes, as overlapping with the status-tradition concerns of influence and prestige. However, stigma additionally results in social distance, which we define as deliberate effort to avoid another or exclude that other from social interaction.

The stigma and status literatures have also tended to deal with different types of social characteristics. Status characteristics theory and research has principally focused on ascribed or task-related attributes such as age, gender, race, and education, whereas the stigma literature primarily addresses behavioral, physical, and illness-related characteristics such as mental disorder, physical disability, HIV/ AIDS, or nontraditional sexual behavior.

We discuss how the processes that lead to status orders may differ from those that produce stigmatization. We develop predictions from the status and stigma literatures and describe an experimental study designed to test the predictions. Experimental conditions differentiated participants from interaction "partners" with respect to attributes studied in prior research as either status characteristics (educational attainment and contrast sensitivity ability) or stigmatizing attributes (mental illness and physical disability). We then measured indicator variables central to status processes (i.e., influence) and to stigma processes (i.e., social distance).

\section{STATUS IN GROUPS}

Status is a position in a group based on esteem and respect. Status characteristics theory (Berger, Cohen, and Zelditch 1972; Berger et al. 1977; Berger, Wagner, and Zelditch 1985) relates characteristics of an individual to that person's rank in a status hierarchy based on the esteem in which the person is held by self and others. According to the theory, group members (often outside their conscious awareness) develop expectations for the performances of themselves and others in the group. In the theory, these expectations are developed based on status characteristics, which are cultural constructions that vary from society to society but have important consequences for relative prestige, power, and 
influence in collectively oriented task groups (Berger et al. 1985). Examples of status characteristics in U.S. culture include race, gender, education, and task expertise. Individuals in categories of status characteristics that produce higher expectations for performance than those of other group members are held in higher esteem, have greater influence on a group's decisions, and have higher positions in the group's status order.

A status characteristic is specific if it carries expectations for competence in a narrow range of situations. Musical talent is a specific characteristic because it only leads to expectations for competence in limited settings. A characteristic is diffuse if it carries with it expectations for competence in a wide variety of situations. Age, gender, race, and social class are examples of diffuse characteristics. In status characteristics theory, both diffuse and specific status characteristics contribute to determining group members' relative status by altering expectations for competence that members hold for one another. Diffuse status characteristics, however, have a moral component not possessed by specific status characteristics, with high status on a diffuse characteristic being viewed as broadly superior to low status on the characteristic (Berger, Rosenholtz, and Zelditch 1980; Webster and Hysom 1998).

Dozens of studies have employed a standard status characteristics theory experimental setting to test elements of the theory and the status-related outcomes of a wide range of attributes. However, mental illness and physical disability have been curiously absent from these investigations. To our knowledge, not a single published research study in the status characteristics theory tradition has examined the status implications of mental illness or physical disability. Wagner (1993) did make a compelling theoretical case for mental illness as a diffuse status characteristic. And, Eiesland and Johnson (1996) proposed that different states of physical ability are differently valued in society, likely leading physical ability to act as a diffuse status characteristic.

The lack of empirical work on mental illness and physical disability in the status tradition may be due to the difficulty of operationalizing them in an experimental setting without arousing suspicion among participants. In other words, while telling participants that they have a partner of the opposite gender may not arouse suspicion, telling them that they have a partner with a mental illness may be difficult to do without producing red flags as to the purposes of the research. Physical disability and particularly mental illness are stigmatizing attributes, which the stigma literature suggests would indicate they should have some of the same consequences in task-oriented groups as low statuses.

\section{STIGMA PROCESSES}

The stigma literature is not guided by a single theoretical framework to the extent that the status literature is. Link and Phelan (2001) provide perhaps the most clearly articulated treatment of the processes that produce stigma. They specify four steps that lead from characteristics that differentiate individuals to unequal outcomes:

1. People distinguish and label human differences.

2. Dominant cultural beliefs link labeled persons to undesirable characteristics. 
3. Labeled persons are placed into categories to accomplish separation of "us" from "them."

4. Labeled persons experience status loss, discrimination, rejection, and exclusion, which lead to negative outcomes such as demoralization, restricted social networks, and reduced earnings (Link et al. 1989).

Early labeling theories posited that societal reaction to deviance created a self-fulfilling prophecy in which the original or primary deviance became heightened and stabilized (Lemert 1974). For example, Scheff (1966) proposed that when residual deviance becomes labeled as mental illness, social pressures to behave in accordance with stereotyped expectations of a person with mental illness can result in the labeled person's acceptance and enactment of the role of a mentally ill person. Link developed his modified labeling theory (Link 1982, 1987) based on a lack of evidence for such a self-fulfilling prophecy in the case of mental illness, paired with a recognition of the validity and importance of other aspects of labeling theory, namely, the role of societal reaction, such as altered social relationships and exclusion from opportunities (Becker 1963; Lemert 1967) in producing negative life outcomes for people labeled as being mentally ill. Link and Phelan's (2001) conceptualization adopts this modified-labeling theory stance with regard to stigmatized characteristics in general; that is, although they do not necessarily produce self-fulfilling prophecies, the social exclusion, blocked opportunities, and disruption to social interaction described in labeling theory have important social and psychological effects on persons with a stigmatized label, including the low power, low prestige, and social influence that are typical of persons with devalued states of a diffuse status characteristic.

Research identifies mental illness as a strongly stigmatized human characteristic (Link et al. 1997; Ritsher and Phelan 2004; Sirey et al. 2001; Wright, Gronfein, and Owens 2000). A label of mental illness elicits broadly negative stereotypes, such as being dangerous, unpredictable, dirty, worthless, weak, and ignorant (Link et al. 1987, 1999; Olmsted and Durham 1976; Phelan et al. 2000; Phelan and Link 2004). The label also causes negative treatment in social interactions (Sibicky and Dovidio 1986), avoidance by others (Link et al. 1999; Phelan 2005), and discrimination in housing, employment, and health care (Brand and Claiborn 1976; Druss et al. 2000; Page and Day 1990).

Physical disability has also been a frequent subject of stigma research. Research generally finds that physical disability is accompanied by stigmatization. ${ }^{1}$ Persons with physical disabilities face employment discrimination, especially for positions that require a high degree of public contact (Bordieri and Drehmer 1986; Bordieri, Drehmer, and Taricone 1990; Gouvier et al. 1991; Premeaux 2001; Ravaud, Madiot, and Ville 1992). Persons without disabilities feel uncomfortable and uncertain when interacting with persons with disabilities, tending to cut short or avoid encounters with persons with disabilities (Fichten

\footnotetext{
${ }^{1}$ Of course, the degree of stigmatization varies as a function of characteristics of the disability, such as its perceived cause (Stone and Colella 1996). In the same way, causal attributions for mental illness affect emotional and behavioral orientations toward ill persons (Corrigan 2000; Phelan 2005). There is an extensive literature on how attributions about illness affect reactions. That work is beyond the scope of the present research. Rather than varying interaction partners on criteria that may affect perceptions of controllability, we seek to introduce interaction partners only distinguished by an illness label, without accompanying information that may lead to differential attributions about controllability. See Corrigan (2000) for a review of research on how attributions about illnesses affect social reactions.
} 
1986; Snyder et al. 1979). And, in general, research finds that persons with disabilities face various forms of devaluation and discrimination (Gerschick and Miller 1995; Groch 1994; Susman 1994).

At the same time, physical disability has been found to elicit a range of positive reactions, such as high impression ratings (Susman 1994), perceptions of honesty and benevolence (Fichten 1986), and tendencies to be viewed as courageous and deserving of a break (Makas 1988). And some research on employment discrimination has found no effects for disability or even effects that favored applicants with disabilities (Cesare, Tannenbaum, and Dalessio 1990; Christman and Slaten 1991; Nordstrom, Huffaker, and Williams 1998).

Despite differences in devaluation attached to mental illness and physical disability, both involve the components of labeling, stereotyping, cognitive separation and status loss, discrimination, rejection, and exclusion identified by Link and Phelan (2001).

\section{COMMON AND DIVERGENT FEATURES OF STIGMA AND STATUS PROCESSES}

Both the stigma and status literatures attend to characteristics that differentiate members of social groups-with some categories viewed more positively and some more negatively than others - and the outcomes produced by this differentiation. However, the characteristics on which the literatures focus and the outcomes to which they attend are different. A question remains as to whether the processes set in motion by a stigmatizing label that produce social rejection and exclusion are fundamentally different from the processes set in motion by a status characteristic that produce differences in influence and performance evaluations. If outcomes central to the status and stigma literatures (influence and social distance, respectively) are not associated with the characteristics studied in both literatures, then we have evidence that the processes are distinct. For example, if status characteristics are associated with differences in influence but not social distance, it would indicate that the status processes that lead to differences in influence are distinct from the stigmatizing processes that lead to differences in social rejection. Research to date, however, has not addressed these distinctions.

It seems clear that not all low states of status characteristics are stigmatized. Those in lowstatus categories of gender, age, and task ability, for example, typically do not face social rejection and exclusion based on their standing on the characteristics. In fact, research has found status hierarchies to be integrating, pulling members, especially high-status members, into a group (Lovaglia and Houser 1996). It is less clear whether all stigmatized characteristics act as status characteristics. Does mental illness act as a status characteristic? Does physical disability? Cancer? Specifying the processes set in motion by status characteristics and stigmatizing labels may help unravel distinctions between the processes as well as points of overlap.

Status characteristics theory contains an explicitly formulated set of criteria about the processes that produce diffuse status characteristics in collectively oriented task groups (Berger et al. 1977). These are as follows: 
1. A characteristic must have states that are differentially evaluated.

2. To each state of the characteristic there corresponds a distinct set of specifically evaluated performance expectations.

3. To each state of the characteristic there corresponds a general performance expectation consistent with the specifically evaluated expectations.

Status characteristics theory does not propose that any particular attributes act as status characteristics. Rather, it specifies the processes set in motion if some attribute is a status characteristic. The three aforementioned criteria can be applied to evaluate whether, according to the theory, any particular attribute is likely to act as a diffuse status characteristic.

In the case of mental illness, it appears that the elements to produce a diffuse status characteristic are in place (Wagner 1993). To be a diffuse status characteristic, mental illness must first be considered unwanted or less desirable than other states of mental health. Research indicates that this is the case (Phelan et al. 2000; Sibicky and Dovidio 1986). Second, mental illness must be associated with specific performance expectations. Persons with mental illnesses are perceived as more likely than others to behave unpredictably, make irrational decisions, and injure others. Third, there must be a general expectation associated with those with mental illness as being less capable than others. Findings on discrimination faced by those with mental illness, as well as research showing that mentally ill persons are viewed as less competent than others at most daily life tasks, indicate that this criterion likely holds (Brand and Claiborn 1976; Druss et al. 2000; Pescosolido et al. 1999).

The case for physical disability operating as a status characteristic is more tenuous. Although results are mixed on performance evaluations for disabled versus nondisabled persons, research is relatively consistent in finding lower performance expectations for disabled than for nondisabled persons (Bowman 1987; Fuqua, Rathbun, and Gade 1984; Hastorf, Northcraft, and Picciotto 1979; Krefting and Brief 1976; Schloss and Soda 1989). In other words, research finds that individuals tend to expect less competent performances from physically disabled than from nondisabled persons, even if they do not evaluate their subsequent performances more negatively. For this reason, we propose that physical disability will act as a diffuse status characteristic in that it satisfies the three criteria necessary for a diffuse status characteristic: physical disability is considered less desirable than not having a disability, persons with disabilities are seen as less capable at a number of tasks than physically able persons, and general performance expectations favor the physically abled relative to the disabled.

Most diffuse status characteristics share three of the four steps in the process that Link and Phelan (2001) specify as producing stigma. Gender, age, social class, and education, for example, all involve people labeling human differences (Step 1), linking low-status persons to undesirable characteristics (Step 2), and discrimination resulting in unequal outcomes (Step 4). It is in the separation of individuals into cognitive categories of "us" and "them" and seeking social and physical separation that many diffuse status characteristics may differ 
from stigmatizing characteristics. Categorizations on the status characteristics of gender or age, for example, do not tend to lead to social rejection or exclusion.

Conceptualizations of stigma and status also identify why there may be a stigma process that goes beyond status loss. While status characteristics such as education have higher and lower levels, both are considered standard or "normal." In contrast, stigma implies the comparison of a standard and a nonstandard or "deviant" characteristic. Thus, in addition to being below a mentally healthy person in a status hierarchy, a mentally ill person may also be subject to a horizontal "usthem" separation and consequently may experience a degree of social rejection that another lower status person would not. Second, members of status groups based on attributes such as gender and education have regular interactions that are guided by mutually agreed upon hierarchies and influence patterns. These "modular schemas" (Ridgeway 2006) should ease interaction because interactants know how to behave. The same is not true for interactions between stigmatized and nonstigmatized individuals. A key aspect of stigma as described by Goffman (1963) and Jones et al. (1984; see also Blascovich et al. 2001; Cahill and Eggleston 1994) is that the presence of the stigmatized characteristic disrupts interactions, causing discomfort and awkwardness, particularly for the "normal," because he or she, lacking a modular schema for interactions with a stigmatized person, does not know what to expect from or how to behave with the person. This discomfort experienced by normals can induce social distance from the stigmatized: discomfort can be averted by avoiding interactions altogether. Therefore, although we expect that both low status and stigmatizing labels will lead to lower influence, we expect only stigmatizing attributes to lead to a desire for social distance.

Finally, status characteristics theory proposes a specific process by which individuals attend to multiple attributes in a situation; that is, individuals act as though they aggregate the expectations of all relevant attributes in developing performance expectations for self and others. For example, the theory would predict that an individual with the low state of a single diffuse status characteristic would be accorded lower performance expectations than another individual with the low state of that same status characteristic but the high state of an additional status characteristic. Thus, we predict that ability at the group task will increase the influence of individuals with both the low states of diffuse status characteristics and stigmatizing attributes. However, because status characteristics theory does not address the outcome of social rejection, and because there is no consistent body of stigma research on how individuals attend to multiple attributes, we make no predictions about how individuals aggregate relevant characteristics in decisions about social rejection.

It is impossible to determine whether all status characteristics act as stigmas or whether all stigmas act as diffuse status characteristics. We can, however, examine attributes known to be status characteristics and attributes known to be stigmatizing to determine whether they produce divergent outcomes. We can also investigate whether attributes known to be stigmatizing combine with other characteristics in ways different from attributes known to be status characteristics. 


\section{RESEARCH STRATEGY AND PREDICTIONS}

We designed an experimental study to test basic questions regarding relationships between status and stigma processes. We first chose two characteristics commonly studied in the status literature and two characteristics commonly studied in the stigma literature and measured effects of those characteristics on two central variables relating to status and stigma - influence and social distance. We expect all four labels to affect influence, but only the so-called stigmatized characteristics to increase social distance.

We chose influence as one dependent variable because it is a key behavioral indicator of the consequences of status in the status literature (and we also believe it should reflect the status loss described in the stigma literature). Although Link and Phelan (2001) propose a number of stigma-related outcomes we might have measured, we chose social distance. It is the most prominent outcome associated with stigma. Also, it is a measure of the distinction between stigma and status discussed previously, namely, that low prevalence and designation as "abnormal," as opposed to merely lower status, causes an additional dimension to stigmasocial rejection - that is not predicted by status characteristics theory to be affected by lowstatus labels.

No single attribute can serve as a prototype of either status characteristics or stigmatized characteristics in general. For example, mental illness is the most commonly studied stigmatized characteristic, but it is associated with particular stereotypes and behavioral expectations that are not shared equally by other stigmatized characteristics such as physical disability or sexual minority status. Our research strategy required that we choose particular characteristics to study. We chose educational attainment and task ability (operationalized in the study as "contrast sensitivity ability," a purportedly little understood perceptual ability) as status characteristics to study and mental illness and physical disability to represent stigmatized attributes. One consideration in these choices was a desire to choose "pure" status and stigmatized characteristics, rather than characteristics such as race or homelessness, which many would view as straddling the two domains, representing both diffuse status characteristics and stigmatized attributes. With respect to our hypothesized basis for a distinction between status and stigma, serious mental illness and physical disability are relatively low prevalence and are considered abnormal or deviant, whereas low educational attainment is relatively higher prevalence and is not considered abnormal or deviant. We made these choices with the knowledge that any broad and general conclusions about the relationship between status and stigma processes will require further research that examines a variety of status and stigmatized characteristics.

We do not attempt to empirically trace the full set of processes involved in the enactment of either status hierarchies or stigma. For example, we do not measure performance expectancies that are part of the status process or stereotypes that play a part in the stigma process. Rather, we focus on the beginning point (the application of socially significant labels) and endpoints (loss of influence and social rejection) of the two sets of processes as the first step in our research program. 
The design we employ is a modification of a standard one in the status literature: status is experimentally manipulated via a label applied to a fictitious partner, and influence is measured in terms of the research participant's tendency to reject influence attempts from the "partner." We augment this design to incorporate stigma processes by also manipulating labels usually considered as stigmatizing and by measuring the critical stigma outcome of social distance.

Participants in our study interacted with fictitious partners over a computer network. Participants' experimental conditions determined characteristics of their "partners." The study had eight conditions described in the Methods section. Participants completed a task with their partners on which we could measure the extent to which the partner influenced the participant. The design then introduced a behavioral measure of social distance from the partner.

\section{Influence Predictions}

Consistent with our theoretical development, we expected to find influence effects for educational attainment, mental illness, and physical disability:

Hypothesis 1 Individuals working with a partner with (a) low educational attainment, (b) a mental illness, or (c) a physical disability will be less influenced by their partners' contributions than individuals working with a partner of equal status (a control condition).

Consistent with status characteristics theory, we predict that individuals will combine all relevant attributes in developing expectations for performance on the group's task.

Hypothesis 2 Partners who have high task ability will have greater influence on individuals than otherwise identical partners who do not have high task ability.

\section{Social Distance Predictions}

We expect to find social distance effects for mental illness and physical disability but not for educational attainment:

Hypothesis 3 In comparison to partners like themselves (the control condition), individuals will be more likely to socially reject partners with (a) a mental illness or (b) a physical disability.

Research consistently demonstrates mental illness to be a stigmatizing attribute. Although less consistent, the literature also generally supports physical disability as a stigmatizing attribute. We do not expect low standing on educational attainment, a standard diffuse status characteristic, to lead to social rejection. We do not have a sufficient basis for predicting the impact of positive status information in the form of high ability at the group's task to reduce social distance. $^{2}$ 


\section{METHODS}

\section{Study Design and Conditions}

We designed an experimental study in which participants interacted in task groups with fictitious partners whom they believed were real. Upon signing up, participants believed that the study would be completed in two phases a week apart. At the beginning of the first phase of the study, participants completed an information form that, in addition to basic demographic questions, included a question about recent hospitalizations. Participants completed a first task working alone and then received a copy of the information form purportedly completed by their "partners." Participants then completed a task in which they had opportunities to be influenced by the partner. They then signed up for the next phase of the study to be completed the following week. In signing up for the next phase of the study, participants had the opportunity to socially reject the partner. The study had eight conditions as follows:

Condition 1, control: The partner had completed a high school degree and had not been hospitalized in the previous 12 months.

Condition 2, low education: The partner's highest education level completed was "10th grade," and the partner had not been hospitalized in the previous 12 months.

Condition 3, mental illness: The partner had completed a high school degree and had an inpatient hospitalization in the previous 12 months. Under the reason for the hospitalization, the partner had written "Psychological problems."

Condition 4, physical disability: The partner had completed a high school degree and had an inpatient hospitalization in the previous 12 months. Under the reason for the hospitalization, the partner had written "My legs are paralyzed."

Condition 5, control + high task ability: The partner had completed a high school degree, had not been hospitalized in the previous 12 months, and had high ability on the group's task.

Condition 6, low education + high task ability: The partner's highest education level completed was "10th grade," the partner had not been hospitalized in the previous 12 months, and the partner had high ability on the group's task.

Condition 7, mental illness + high task ability: The partner had completed a high school degree and had an inpatient hospitalization in the previous 12 months. Under the reason for the hospitalization, the partner had written "Psychological problems." Additionally, the partner had high ability on the group's task.

Condition 8, physical disability + high task ability: The partner had completed a high school degree and had an inpatient hospitalization in the previous 12 months. Under the

\footnotetext{
${ }^{2}$ The "master status" concept in the labeling perspective suggests that the addition of task ability information will not reduce social rejection of partners with mental illness or physical disabilities on an activity with no task implications. According to master status arguments, a master status overrides other attributes in reactions to the individual such that others only view the person in terms of the stigmatized label (Becker 1963). However, empirical support for master status arguments has been mixed, and additionally it has ceased to be a major perspective in discussions of the stigma of mental illness. For this reason, we do not use master status accounts as a basis for predictions. We do discuss implications of our findings for the master status conceptualization in the conclusion.
} 
reason for the hospitalization, the partner had written "My legs are paralyzed."

Additionally, the partner had high ability on the group's task.

\section{Procedures}

In addition to operationalizing our independent variables, we had the task in designing our study to construct a method whereby the fictitious partners across conditions would share all information about themselves in the same manner. In other words, our goal was for a participant to learn that a partner had a mental illness in the same manner that a participant learned that a partner had a low level of education. We also sought to introduce the characteristics representing our conditions without introducing any extraneous information. Consistent with the scope of status characteristics theory, we designed a setting in which participants interacted in task- and collectively oriented groups. And, we sought to develop a behavioral social distance measure that would decrease the likelihood that participants would choose not to socially reject a partner for fear of being judged negatively by the experimenter or hurting the partner's feelings.

When signing up for the study, participants were told that the study would be completed in two phases to be carried out a week apart. Upon arriving for the study, participants were given a sheet of paper with an identification number that they were told they would need later in the study. Research assistants then gave participants a form titled "Research Participant Disclosure Form.” The form was on university letterhead, and research assistants explained to participants that the university required the form to be completed by all participants in any research study carried out at the university. The form asked participants their age, highest education level completed, and whether they were eligible for legal employment in the United States. A final question asked participants if they had an inpatient hospitalization for any condition in the previous 12 months, and if so, the condition requiring hospitalization. ${ }^{3}$

Computer instructions informed participants that the two phases of the study would involve different types of activities. In the first week, participants would complete two tasks, one working alone and one with a partner on a computer in another room. In the second week, participants would meet with a partner to discuss a social issue in a face-to-face setting. After reading these instructions, participants began the first task. The task was a contrast sensitivity exercise, a standard task in research on status characteristics theory. For each of a number of questions, participants identified whether they believed that a rectangle on the computer screen had a greater shaded (black) or nonshaded (white) area. Instructions informed participants that some persons have more "contrast sensitivity ability" than others and are able to identify slight differences in the types of shapes they were studying. Each rectangle that participants judged was in fact roughly half shaded and half nonshaded.

After participants completed the first task, instructions informed them that although groups working over computer networks is becoming more and more common, members of these groups usually know a little bit about each other. For this reason, instructions said, a research assistant would be in the room to collect information from the participant to share

\footnotetext{
${ }^{3}$ Research assistants shredded participants' forms immediately after leaving participants' rooms.
} 
with her or his partner. When the research assistant entered the room, she or he informed the participant that although the computer instructions said that we would be collecting information, because study participants had already completed the disclosure form at the beginning of the study, we would instead crop names off the forms and share the participant's disclosure form with the partner and the partner's form with the participant.

The research assistant then left the room and returned with a photocopied Research Participant Disclosure Form that had the name and signature sections removed. Research assistants informed participants that they were receiving a copy of the partner's form. Printed in large characters on the top of the form in red ink and circled was an identification number. The number was very similar to the participants' number, differing only in the last character. The information on the disclosure form was determined by the participant's condition as described previously.

After receiving the partner's disclosure form, participants read instructions about the second task. Instructions informed them that the second task would include 25 contrast sensitivity problems, each involving the selection of which of two rectangles had a greater shaded area. For each question, they would make an initial selection, see their partner's initial selection, and then make a final selection. Instructions noted that a group score would be tabulated based on the total number of correct final answers provided by both partners and that pay for the study would be based on this group score. ${ }^{4}$ Participants then began the second task.

After participants completed the second task, a computer screen informed them that this week's session of the study was complete and that it was time to sign up for the phase to be completed in the following week. Instructions informed participants that they would select a discussion topic that they would like to talk about in their group the next week. The second phase of the study was described to participants as a social activity involving an informal discussion. A research assistant entered the room, opened a spreadsheet on the participant's computer, told the participant to select the topic she or he would like to discuss the following week, and then left the room.

On the spreadsheet, participants saw three discussion topics and a note that only two persons could sign up for any one topic. Instructions told participants to type their identification numbers under the available topic they would like to discuss. Participants were able to see that one of the topics had two identification numbers under it and was thus not available. The other two topics each had one identification number and one open space. ${ }^{5}$ The participant selected a topic for the following week's discussion and the study was complete. Participants were then debriefed and paid. They did not in fact return to the lab for a second phase of the study the following week.

\footnotetext{
${ }_{5}^{4}$ All participants were in fact paid $\$ 20$.

5 We pretested the topics we used in the study by asking students in undergraduate classes to express their interest in discussing a number of topics. We took the two topics that received the mean interest scores closest together and made these the two topics available to participants.
} 


\section{Independent Variables}

The study had eight conditions that varied by characteristics of participants' partners. We controlled information about partners through information on the "disclosure form" and computerized feedback on the first task. On the disclosure form, all "partners" had circled a box for the age range 18-25 and indicated that they were eligible for legal employment in the United States; the form did not have an item for gender, and we did not share with participants information about the partner's gender. We varied information participants received on the partner's disclosure form on items asking highest education level completed and hospitalization history.

In response to the question asking highest education level completed, partners in all conditions except Conditions 2 and 6 circled that their highest education level completed was a high school degree. This matched the response for all participants. In Conditions 2 and 6 , in which we attempted to create partners with low status on educational attainment, partners had indicated that their highest education level completed was 10th grade. ${ }^{6}$

The question about hospitalization history asked if respondents had been hospitalized for any reason in the previous 12 months and if so, the reason. In Conditions 1, 2, 5, and 6, partners circled no in response to the question. In Conditions 3 and 7, partners circled yes and wrote that they had been hospitalized for "psychological problems." Partners in Conditions 4 and 8 also circled yes, and for the reason of the hospitalization wrote "My legs are paralyzed."

We made our manipulation of mental illness ("psychological problems") deliberately broad. At the same time, we feel it is a powerful manipulation of mental illness. Although increasing numbers of Americans are being medicated for mental illness, inpatient hospitalizations for mental illness are still very low prevalence. Thus, when participants learned the partner was hospitalized for "psychological problems," our expectation was that they would take more from the fact that the partner was hospitalized for mental illness than from the partner's perhaps benignseeming characterization of the hospitalization as being related to "psychological problems." In contrast to our broad manipulation of mental illness, our manipulation of physical disability ("paralyzed legs") was relatively more specific.

To create conditions of high task ability, we gave participants information on their and their partners' scores on the first task that was completed alone. In Conditions 1 through 4 , participants first completed the task working alone-which we described to them as serving to familiarize them with task problems - and then simply moved on to the group task. In Conditions 5 through 8, the computer instructed participants to wait after the first task was completed while group scores were tabulated. A screen then appeared that showed participants their own and their partners' scores on the first contrast sensitivity task.

\footnotetext{
${ }^{6}$ The disclosure form allowed participants the following options for educational attainment: high school degree, college degree (e.g., BA), advanced degree (e.g., MA or PhD), or other. The "other" option provided a space to write in the highest education level completed. All participants in the study circled "high school degree" for highest education level completed. "Partners" in all conditions other than Conditions 2 and 6 circled "high school degree." In Conditions 2 and 6, partners circled "Other" and wrote in "10th grade."
} 
Participants in Conditions 5 through 8 saw that they themselves scored 7 out of 25 trials correctly while their partners scored 19 out of 25 correctly.

\section{Dependent Variables}

Our influence measure came from the second contrast sensitivity task in which participants worked with their "partners" to solve task problems. Participants and partners always initially disagreed on 20 of the 25 contrast sensitivity questions. We measured resistance to partner influence by the number of times in these 20 opportunities that participants did not switch their answers to correspond with the initial answer provided by the partner.

We measured social distance by participants' topic selections for the second phase of the study. When selecting among the two open topics for the following week, by knowing the partner's identification number from the disclosure form, participants were able to see that the partner had signed up for one of the topics. Thus, although participants were ostensibly selecting the topic they found most interesting, they also had the option of signing up to be with the same or a new partner for the following week. We believed that the stated purpose of selecting a topic rather than a person, as well as the fact that participants could easily claim that they were either not aware of or not considering the partner's identification number when selecting a topic, would decrease the likelihood that social desirability biases would impact participants' decisions on whether to select a new partner. ${ }^{7}$ We measured social distance by how often participants in a condition selected a new partner for the second phase of the study.

\section{Sample and Manipulation Checks}

Participants were 323 students at a large state university. Of these, 227 were women and 96 were men. The participants were all college students between 18 and 25 years old who had completed a high school degree as their highest level of educational attainment. We followed procedures of random assignment to assign 40 or 41 participants to each condition. 8

In debriefing, research assistants told participants that partners in the study were not real and that we systematically varied characteristics of partners in the study. Research assistants asked the participants questions to see if they could correctly identify their partners' characteristics. All participants in the study correctly identified the attributes of their partners.

Research assistants also gauged participants' levels of suspicion with the manipulation. We first asked participants if they suspected during the study that the partner was not real. If a participant answered yes, we then asked his or her level of suspicion (e.g., wondered if the partner wasn't real vs. feeling reasonably certain the partner wasn't real). We also asked

\footnotetext{
${ }^{7}$ After participants signed up for the following week, they answered 20 questionnaire items on their computer screens. These included items designed to measure common outcomes in both the status and stigma literatures. Analyses of questionnaire items are available from the authors.

${ }^{8}$ We ran the study in two iterations. We first randomly assigned participants to conditions until one condition reached 30 participants. We then randomly assigned to remaining conditions until all conditions had reached 30 participants. We then followed the same approach until all conditions had reached 40 participants. The result was that all conditions had 40 or 41 participants.
} 
participants how their suspicion affected their behavior on the study. If participants indicated that they believed the partner was not real and indicated that this suspicion led them to behave in particular ways (e.g., ignoring the partner's ID number when signing up for the second phase), we rejected the participant's data for excessive suspicion. In all, we excluded data from 13 participants for excessive suspicion.

A number of participants indicated in debriefing that they did not notice the partner's ID on the signup sheet when selecting a discussion topic for the following week. We believed it would be unlikely for a participant to not notice the partner's ID and also that social desirability reasons drove some participants to say they did not see the ID (i.e., participants chose to reject the partner but indicated that they did not know they were doing so). We chose not to reject data from these participants. There are likely some participants in our data who in fact did not notice the partner's ID when selecting a topic, but we can think of no reason why this would systematically vary across conditions, and the most likely effect of including data from these participants in our analyses is reducing variability on our social distance measure across conditions.

In debriefing, we asked participants questions to gauge whether we satisfied the task orientation and collective orientation scope conditions of status characteristics theory. These included asking participants whether it was important to them to do well on the group task, whether they tried their hardest on the task, and whether they took their partners' answers into account. We rejected data from 3 participants for violations of the scope of status characteristics theory. In all, we excluded data from 16 participants (4.7 percent of all participants) because of either excessive suspicion or violations of the scope conditions of status characteristics theory.

\section{RESULTS}

\section{Influence}

Table 1 displays mean differences on influence and results of significance tests. Influence represents the number of times in 20 initial disagreements that participants switched their answers to correspond to answers provided by their partners. Status characteristics research more commonly reports resistance to influence. This value, observed $\mathrm{p}(\mathrm{s})$, represents the proportion of times participants stayed with their own answers and resisted the partner's influence. In the control condition in which participants on average switched to the partner's answer 9.93 times in 20 opportunities, the $\mathrm{p}(\mathrm{s})$ score is $.5035,(20-9.93) / 20$, meaning that participants remained with their own initial guess on average 50.35 percent of the time. We calculated expected $\mathrm{p}(\mathrm{s})$ across conditions to reflect our hypotheses by using formulas from the formal version of status characteristics theory. The appendix explains how we arrived at expected $\mathrm{p}(\mathrm{s})$ values.

A chi-square test on expected versus observed $\mathrm{p}(\mathrm{s})$ values is small and insignificant $\left(\chi^{2}=\right.$ $24.00, p=.293$ ), indicating that our expected $\mathrm{p}(\mathrm{s})$ values fit the influence data well. The $\mathrm{G}^{2}$ value represents the reduction in chi-square in using our model of status processes across conditions to obtain predicted $\mathrm{p}(\mathrm{s})$ values versus using the overall mean of all observed $\mathrm{p}(\mathrm{s})$ values (see Kalkhoff, Younts, and Troyer 2011). The large $\mathrm{G}^{2}$ value of 87 percent indicates 
a strong improvement in fit in using our expected $\mathrm{p}(\mathrm{s})$ values. Thus, results indicate that our modeling of the status processes involved in our experimental conditions fits the data well.

With support for our overall model, we turned to analyses of predicted differences across conditions. We predicted that low education, mental illness, and physical disability would function as low states of diffuse status characteristics and therefore that partners in Conditions 2, 3, and 4 would have less influence than participants in the control condition (Condition 1). The mean influence score in the control condition was $9.93(\mathrm{SD}=2.36, \mathrm{p}(\mathrm{s})$ $=.5035)$. The mean influence score in the education condition was $8.50(\mathrm{SD}=2.33, \mathrm{p}(\mathrm{s})=$. $5750)$, significantly lower than the control condition $(t=2.83$, one-tailed $p=.003)$, supporting Hypothesis 1(a) and consistent with prior status research. ${ }^{9}$ The mean influence score in the mental illness condition was $8.63(\mathrm{SD}=3.00, \mathrm{p}(\mathrm{s})=.5685)$. This mean was in the predicted direction from the control, and the difference is significant $(t=2.17$, one-tailed $p=.017$ ). This supports Hypothesis 1(b) and indicates that mental illness operated as a status characteristic in our sample. Mean influence in the disability condition was 9.43 (SD $=3.19, \mathrm{p}(\mathrm{s})=.5285)$. This mean was in the predicted direction from the control but not significant $(t=.808$, one-tailed $p=.211)$. Hypothesis $1(\mathrm{c})$ that predicted influence effects for physical disability was not supported.

Hypothesis 2 predicted in line with status characteristics theory that high task ability would increase influence for partners with all attributes we studied. For the control conditions, partners in Condition 5 with high task ability had mean influence of 12.23 ( $\mathrm{SD}=4.26, \mathrm{p}(\mathrm{s})$ $=.3885$ ), compared to partners in Condition 1 without high task ability (i.e., no information on task ability was communicated), who had mean influence of 9.93 . This is a significant difference $(t=3.01$, one-tailed $p=.002)$. Partners with low educational attainment and high task ability had mean influence of $11.58(\mathrm{SD}=4.34, \mathrm{p}(\mathrm{s})=.4210)$, significantly higher than partners with low educational attainment alone $(t=4.01$, one-tailed $p=<.001)$. Partners with mental illnesses and high task ability had mean influence of $11.49(\mathrm{SD}=4.18, \mathrm{p}(\mathrm{s})=$. 4255), significantly higher than partners with mental illness alone $(t=3.53$, one-tailed $p<$. 001). And partners with physical disabilities and high task ability had mean influence of $10.43(\mathrm{SD}=3.80, \mathrm{p}(\mathrm{s})=.4195)$, significantly higher than partners with physical disabilities alone $(t=2.60$, one-tailed $p=.006)$. Thus, results provide strong support for Hypothesis 2 , which predicted that task ability would increase the influence of partners with any attribute (low educational attainment, mental illness, or physical disability).

In all, influence findings supported our predictions well. The exception is that influence in the physical disability condition (Condition 4) was not lower than in the control condition

\footnotetext{
${ }^{9}$ Our design had unequal numbers of male and female participants across conditions. We did not tell participants the gender of partners, and thus from the standpoint of status characteristics theory, we should not expect gender to be salient in the situation. The proportion of women across conditions varied from 63 percent to 75 percent. We ran several analyses in an effort to rule out any effects we found being due to gender. We first compared women and men, irrespective of condition, on all of our outcome measures. Men and women did not significantly differ on influence from partner or on percentage of time selecting a new partner. Three of our self-report items did produce significant differences between women and men. Women on average rated partners as significantly more respected and knowledgeable than did men. Women were also significantly more likely than men to evaluate partners as leaders. We then ran regression models for each dependent variable, comparing each condition to the control condition and including gender as a control. All differences between conditions that were significant in bivariate comparisons, as reported in the Results section, remained significant, and no differences previously not significant emerged as significant.
} 
(Condition 1). Our data thus did not support physical disability acting as a status characteristic in our sample.

\section{Social Distance}

Table 1 also displays results on our measure of social distance. We predicted that the mental illness and physical disability conditions, but not the low education condition, would lead to greater social distance from the partner among participants than the control condition. Our measure of social distance was the behavioral measure of rejection of the partner in signing up for the second task. In the control condition, 39.02 percent of participants signed up to be with a different partner in the second phase of the study than in the first phase. In the low education condition, 40.00 percent of participants signed up to be with a new partner. This difference is not significant (chi-square $=.008, p=.928$ ). In the mental illness condition, 80.0 percent of participants signed up to be with a new partner. This is in the predicted direction from the control and the difference is significant (chi-square $=14.82$, one-tailed $p$ $<.001$ ), supporting Hypothesis 3(a). In the physical disability condition, 57.5 percent of participants signed up to be with a new partner. This is significantly different from the control (chi-square $=3.09$, one-tailed $p=.040$ ), supporting Hypothesis 3(b).

We made no prediction about how the addition of information about task ability would affect social distance from partners with stigmatizing attributes. Groups for the second phase of the study were described multiple times in study instructions as meeting to discuss a social issue (as opposed to task groups), and so status characteristics theory would make no predictions about how multiple characteristics might aggregate. Social distance scores for Conditions 5 through 8 are displayed in Table 1. Of note is that mean social rejection scores are lower in all task ability conditions than in corresponding conditions in which information about task ability was not communicated (e.g., 39.02 percent of partners in the control condition selected a new partner compared to 27.05 percent of participants in the control and high task ability condition). For partners with mental illness, the introduction of high task ability significantly reduced social rejection (chi-square $=8.59, p=.003$ ). Introducing information about task ability also significantly reduced social rejection of partners with physical disability (chi-square $=4.45$, one-tailed $p=.035$ ). Task ability information did not significantly reduce social distance in the control (chi-square $=1.21, p=.271$ ) or education (chi-square $=.213, p=.644$ ) conditions.

In sum, consistent with expectations, our data show significant social rejection of partners with mental illness and physical disability, but not of partners with low educational attainment. In addition, the introduction of information about high task ability appeared to reduce stigmatization in our sample. This finding was interesting in that we made efforts to describe the second phase of the study as purely social, but task ability still benefitted partners.

\section{DISCUSSION}

We expected areas of overlap and departure in measures of the status and stigma attributes we studied. Specifically, we predicted that educational attainment, mental illness, and physical disability would produce status effects but that only mental illness and physical 
disability would produce stigma effects. We also predicted that task ability would increase the influence of persons with stigmatizing attributes just as it would increase the influence of persons with the low state of a diffuse status characteristic. Our predictions were generally well supported.

Educational attainment, consistent with previous research, acted as a status characteristic in our sample. It did not, however, significantly affect social distance. Mental illness produced strong effects on both influence and social distance. We found no significant effects for physical disability on social influence but did find social rejection of partners with disabilities. Although we predicted status effects for disability, our status nonresults are consistent with the literature demonstrating that performance evaluations of persons with physical disabilities are not biased compared to performances from nondisabled persons (e.g., Czajka and DeNisi 1988).

We included conditions in which the partner had high task ability to investigate how responses to the various attributes we employed in Conditions 1 through 4 would vary with the introduction of additional status information. We predicted that partners of all types would benefit from additional information indicating that they had high task ability, giving them greater influence over participants. Results indicated that they did. All partners with high task ability had significantly higher influence than comparable partners without the introduction of information about task ability.

Stigmatized characteristics have sometimes been conceptualized as "master statuses" that override other attributes in reactions to the individual such that others view the person only in terms of the stigmatized label (Becker 1963; Blinde and Taub 1992). If a master status were in play, we would not expect task ability to reduce social distance or increase performance expectations for partners in the mental illness or physical disability conditions. We found no evidence that mental illness or physical disability operated as master statuses. Partners with stigmatizing attributes were less frequently rejected when they had high task ability. This result was most clear-cut for mental illness. Whereas 80.0 percent of participants with a mentally ill partner selected a new partner for the second phase of the study, 48.78 percent who had a mentally ill partner with high task ability chose a new partner. This difference is significant. Adding task ability produced findings in the direction of less social rejection for other conditions as well, with the difference in the physical disability conditions being significant. We did not expect these findings in part because instructions explicitly described the second phase as meeting to discuss a social issue, thus placing the setting outside the scope of status characteristics theory, which applies to groups engaged in collective tasks.

It may be that adding information about task ability reduced social distance. It also may be that participants in conditions in which information about task ability was not communicated felt they had the "power" to stigmatize, whereas participants in other conditions did not. The expectation advantage figures in the appendix show that in the conditions in which partners had high task ability, but not in other conditions, participants were at a status disadvantage relative to the partner; that is, the model predicts that participants will be status advantaged or status equals relative to partners in Conditions 1 through 4 but status disadvantaged in 
Conditions 5 through 8 . In that power to stigmatize is theorized as an element of the stigma process (Link and Phelan 2001), it is possible that participants in these status disadvantaged conditions did not feel that they were in positions to socially reject others. ${ }^{10}$

Results from task ability conditions, then, show strong benefits from task ability in terms of influence, whether the partner had low status on a status characteristic as traditionally conceived or a stigmatizing attribute. Results on social distance indicate that task ability mitigates against stigmatization as well, especially for mental illness. This is particularly notable because mental illness is among the most strongly stigmatized characteristics (Westbrook, Legge, and Pennay 1993) and might be particularly expected to act as a master status. It should be noted that task ability is a specific status characteristic, in contrast to diffuse status characteristics such as educational attainment. Future research should examine whether master status effects are found when a stigmatized status such as mental illness is combined with a diffuse rather than a specific status characteristic. Nevertheless, our findings that task ability may reduce social rejection are important in themselves and have implications for stigma reduction strategies.

A limitation of this research is that only four characteristics were studied. More general conclusions will depend on replication with a variety of status characteristics and stigmatized attributes. Clearly, not all stigmas are created equal. Although the results for mental illness and physical disability were in the same direction on our behavioral measures of influence and social distance, differences from the control group were much larger for mental illness and only the mental illness condition was significantly different from the control on influence. We might conclude that physical disability as operationlized in our study (a person whose legs are paralyzed) is not a status characteristic. Link and Phelan (2001), however, argue that stigma is a matter of degree and that the severity of stigma attached to different characteristics varies. From this perspective, and given the support for our overall model, it is possible that physical disability as operationalized in our study acts as a status characteristic in our sample but less intensely than mental illness.

An additional limitation to the study is that participants might have drawn multiple conclusions about our operationalization of mental illness. Because we used an abstract representation of mental illness ("psychological problems"), participants might have drawn multiple conclusions about reasons for the partner being hospitalized. And, the introduction of information about task ability may have changed these conclusions. In other words, it may be that task ability itself did not increase influence of partners with mental illness, but instead changed assumptions about the mental illness. ${ }^{11}$ However, despite the abstractness of the phrase "psychological problems," the information that the partner was hospitalized for those problems limits the range of possible interpretations participants might apply to "psychological problems." The fact of hospitalization suggests that the psychological problems, whatever their exact nature, were quite serious.

\footnotetext{
${ }^{10}$ We thank an anonymous $S P Q$ reviewer for making the point that status (dis)advantage may have led participants to feel that they did or did not have the power to stigmatize partners across conditions.

${ }^{11}$ We thank an anonymous $S P Q$ reviewer for pointing this out.
} 
We would like to highlight three conclusions that represent important contributions of this research. First, mental illness behaved as a status characteristic in our sample. Second, our social distance measure behaviorally captured effects in directions consistent with selfreport stigma items in prior research. Third, for both performance expectations and social distance, stigmatized attributes combined with other characteristics in a process consistent with that described by status characteristics theory.

On the first conclusion, although Wagner (1993) developed an argument for why mental illness has the necessary elements to act as a diffuse status characteristic, no research in the status characteristics program has tested for status effects of mental illness. Our design produced status outcomes for mental illness that were very similar to those produced by low educational attainment. This research suggests a place for mental illness in the status characteristics theory program of research. Future research will be valuable in determining whether these effects can be replicated and, if so, answering additional questions, such as how mental illness combines with diffuse status characteristics in affecting influence and whether interventions that have been successful in status characteristics research will extend to mental illness.

Second, our behavioral social distance measure appeared to successfully circumvent social desirability effects that may have made participants reluctant to reject mentally ill and physically disabled partners. If future research finds similar effects, we will have a setting well equipped to study the utility of anti-stigma interventions. The setting can also allow for the study of different categories of mental illness. In constructing our design, we were faced with the decision of having the partner in the mental illness condition list a history of mental illness in general terms or to list a particular illness. Future research might build on our general approach by measuring outcomes across different categories of mental illness.

Third, we found strong evidence that combining stigmatizing attributes with task ability positively affected expectations for performance. We did not find that stigmatizing attributes overwhelmed other characteristics in affecting influence. These findings suggest that the stigmatizing attributes we studied operated just as do status characteristics in settings within the scope of status characteristics theory.

Finally, our finding suggesting that task ability might reduce social distance is a potentially fruitful topic for future research. Contrary to the notion that a label of mental illness evokes such strongly negative reactions that other information about a mentally ill person is discounted, task ability significantly reduced social distance from a person identified as having been hospitalized for psychological problems or a physical disability in the prior 12 months. Efforts to combat stigma have been limited in their success, and our findings suggest that making persons explicitly aware of the competencies of persons with mental illnesses or physical disabilities might reduce social rejection even in settings unrelated to those competencies. Our findings resonate with research showing that direct contact with a mentally ill person is currently the most effective approach to reducing mental illness stigma (Reinke et al. 2004). It seems likely that contact reduces stigma in large part because real persons with mental illness generally show themselves to be more competent than the stereotypes imagined by most people. By explicitly highlighting competence in contact 
interventions, as has been done in interventions based on status characteristics theory (e.g., Cohen and Lotan 1995), it may be possible to further enhance the stigma-reducing effects of contact interventions.

We consider our findings to be only a first step in the exploration of concerns that span the stigma and status literatures, and we hope they will be an impetus for future research on these questions. As illustrated by the distinct results for mental illness and physical disability, it will be important to consider a broad array of such attributes to draw more general conclusions about how the effects of stigmatized and status characteristics compare. Other aspects of both status and stigma processes should also be considered, such as how processes involved in identifying and labeling differences may be distinct for status characteristics and stigmatizing attributes. Although the experimental method was extremely valuable for our purposes, other methodologies can be brought to bear on these issues.

\section{Acknowledgments}

We thank Joseph Berger, Amerigo Farina, Bruce Link, Cecilia Ridgeway, and David Wagner for valuable assistance in the design of the study. We thank Lisa Troyer for making available to us the computer software she developed for administering contrast sensitivity tasks in experimental studies.

\section{FUNDING}

The author(s) disclosed receipt of the following financial support for the research, authorship, and/or publication of this article: This research was supported in part by NIMH grants K02 MH65330 and R01 MH079162.

\section{References}

Becker, Howard S. Outsiders: Studies in the Sociology of Deviance. New York: Free Press; 1963.

Berger, Joseph; Cohen, Bernard P.; Zelditch, Morris, Jr. Status Characteristics and Social Interaction. American Sociological Review. 1972; 37:241-55.

Berger, Joseph; Hamit Fisek, M.; Norman, Robert Z.; Zelditch, Morris, Jr. Status Characteristics and Social Interaction: An Expectation States Approach. New York: Elsevier; 1977.

Berger, Joseph; Rosenholtz, Susan J.; Zelditch, Morris, Jr. Status Organizing Processes. Annual Review of Sociology. 1980; 6:477-508.

Berger, Joseph; Wagner, David G.; Zelditch, Morris, Jr; Berger, J.; Zelditch, M, Jr. Status, Rewards, and Influence. San Francisco: Jossey-Bass; 1985. Introduction: Expectation States Theory: Review and Assessment; p. 1-72.

Blascovich, Jim; Mendes, Wendy Berry; Hunter, Sarah B.; Lickel, Brian; Kowai-Bell, Neneh. Perceiver Threat in Social Interactions with Stigmatized Others. Journal of Personality and Social Psychology. 2001; 80:253-67. [PubMed: 11220444]

Blinde, Elaine M.; Taub, Diane E. Women Athletes as Falsely Accused Deviants: Managing the Lesbian Stigma. The Sociological Quarterly. 1992; 33:521-33.

Bordieri, James E.; Drehmer, David E. Hiring Decisions for Disabled Workers: Looking at the Cause. Journal of Applied Social Psychology. 1986; 16:197-208.

Bordieri, James E.; Drehmer, David E.; Taricone, Patrick F. Personnel Selection Bias for Job Applicants with Cancer. Journal of Applied Social Psychology. 1990; 20:244-53.

Bowman, James T. Attitudes toward Disabled Persons: Social Distance and Work Competence. Journal of Rehabilitation. 1987; 53:41-4.

Brand, R Curtis; Claiborn, William L. Two Studies of Comparative Stigma: Employer Attitudes and Practices toward Rehabilitated Convicts, Mental and Tuberculosis Patients. Community Mental Health Journal. 1976; 12:168-75. [PubMed: 1277781] 
Cahill, Spencer E.; Eggleston, Robin. Managing Emotions in Public: The Case of Wheelchair Users. Social Psychology Quarterly. 1994; 57:300-12.

Cesare, Steven J.; Tannenbaum, Richard J.; Dalessio, Anthony. Interviewers' Decisions Related to Applicant Handicap Type and Rater Empathy. Human Performance. 1990; 3:157-71.

Christman, Lisa A.; Lewis Slaten, B. Attitudes toward People with Disabilities and Judgments of Employment Potential. Perceptual and Motor Skills. 1991; 72:467-75. [PubMed: 1830139]

Cohen, Elizabeth G.; Lotan, Rachel A. Producing Equal-Status Interaction in the Heterogeneous Classroom. American Educational Research Journal. 1995; 32:99-120.

Corrigan, Patrick. Mental Health Stigma as Social Attribution: Implications for Research Methods and Attitude Change. Clinical Psychology: Science and Practice. 2000; 7:48-67.

Czajka, Joseph M.; DeNisi, Angelo S. Effects of Emotional Disability and Clear Performance Standards on Performance Ratings. Academy of Management Journal. 1988; 31:394-404.

Druss, Benjamin G.; Marcus, Steven C.; Rosenheck, Robert A.; Olfson, Mark; Tanielian, Terri; Pincus, Harold A. Understanding Disability in Mental and General Medical Conditions. American Journal of Psychiatry. 2000; 157:485-91. [PubMed: 10698850]

Eiesland, Nancy L.; Johnson, Cathryn. Physical Ability as a Diffuse Status Characteristic: Implications for Small Group Interaction. In: Markovsky, B.; Lovaglia, MJ.; Simon, R., editors. Advances in Group Processes. Vol. 13. Greenwich, CT: JAI Press; 1996. p. 67-90.

Fichten, Catherine S. Self, Other, and Situation-Referent Automatic Thoughts: Interaction between People Who Have a Physical Disability and Those Who Do Not. Cognitive Therapy and Research. 1986; 10:571-88.

Fuqua, Dale R.; Rathbun, M.; Gade, Eldon M. A Comparison of Employer Attitudes toward the Worker Problems of Eight Types of Disabled Workers. Journal of Applied Rehabilitation Counseling. 1984; 15:40-43.

Gerschick, Thomas J.; Miller, Adam Stephen. Coming to Terms: Masculinity and Physical Disability. In: Sabo, D.; Gordon, DF., editors. Men's Health and Illness: Gender, Power, and the Body. Thousand Oaks, CA: Sage; 1995. p. 183-204.

Goffman, Erving. Stigma: Notes on the Management of Spoiled Identity. Englewood Cliffs, NJ: Prentice Hall; 1963.

Gouvier, William Drew; Steiner, Dirk D.; Jackson, Warren T.; Schlater, David; Rain, Jeffrey S. Employment Discrimination against Handicapped Job Candidates: An Analog Study of the Effects of Neurological Causation, Visibility of Handicap, and Public Contact. Rehabilitation Psychology. 1991; 36:121-29.

Groch, Sharon A. Oppositional Consciousness: Its Manifestations and Development. Sociological Inquiry. 1994; 64:369-95.

Hastorf, Albert H.; Northcraft, Gregory B.; Picciotto, Samuel R. Helping the Handicapped: How Realistic Is the Performance Feedback Received by the Physically Handicapped? Personality and Social Psychology Bulletin. 1979; 5:373-76.

Jones, Edward E.; Farina, Amerigo; Hestrof, Albert H.; Markus, Hazel; Miller, Dale T.; Scott, Robert A. Social Stigma: The Psychology of Marked Relationships. New York: W.H. Freeman \& Co; 1984.

Kalkhoff, Will; Wesley Younts, C.; Troyer, Lisa. Do Others' Views of Us Transfer to New Groups and Tasks?: An Expectation States Approach. Social Psychology Quarterly. 2011; 74:267-90.

Krefting, Linda A.; Brief, Arthur P. The Impact of Applicant Disability on Evaluative Judgments in the Selection Process. Academy of Management Journal. 1976; 19:675-80.

Lemert, Edwin M. Human Deviance, Social Problems and Social Control. Englewood Cliffs, NJ: Prentice Hall; 1967.

Lemert, Edwin M. Beyond Mead: The Societal Reaction to Deviance. Social Problems. 1974; 21:45768.

Link, Bruce. Mental Patient Status, Work, and Income: An Examination of the Effects of a Psychiatric Label. American Sociological Review. 1982; 47:202-15. [PubMed: 7091929]

Link, Bruce G. Understanding Labeling Effects in the Area of Mental Disorders: An Assessment of the Effects of Expectations of Rejection. American Sociological Review. 1987; 52:96-112. 
Link, Bruce; Cullen, Francis; Frank, James; Wozniak, John F. The Social Rejection of Former Mental Patients: Understanding Why Labels Matter. American Journal of Sociology. 1987; 92:1461-500.

Link, Bruce G.; Cullen, Francis T.; Struening, Elmer L.; Shrout, Patrick E.; Dohrenwend, Bruce P. A Modified Labeling Theory Approach in the Area of Mental Disorders: An Empirical Assessment. American Sociological Review. 1989; 54:100-23.

Link, Bruce G.; Phelan, Jo C. Conceptualizing Stigma. Annual Review of Sociology. 2001; 27:36385.

Link, Bruce G.; Phelan, Jo C.; Bresnahan, M.; Stueve, Ann; Pescosolido, Bernice A. Public Conceptions of Mental Illness: Labels, Causes, Dangerousness and Social Distance. American Journal of Public Health. 1999; 89:1328-33. [PubMed: 10474548]

Link, Bruce G.; Struening, Elmer L.; Rahav, Michael; Phelan, Jo C.; Nuttbrock, Larry. On Stigma and Its Consequences: Evidence from a Longitudinal Study of Men with Dual Diagnoses of Mental Illness and Substance Abuse. Journal of Health and Social Behavior. 1997; 38:177-90. [PubMed: 9212538]

Lovaglia, Michael J.; Houser, Jeffrey A. Emotional Reactions and Status in Groups. American Sociological Review. 1996; 61:867-83.

Makas, Elaine. Positive Attitudes toward Disabled People: Disabled and Nondisabled Persons' Perspectives. Journal of Social Issues. 1988; 44:49-61.

Nordstrom, Cynthia R.; Huffaker, Bill J.; Williams, Karen B. When Physical Disabilities Are Not Liabilities: The Role of Applicant and Interviewer Characteristics on Employment Interview Outcomes. Journal of Applied Social Psychology. 1998; 28:283-306.

Olmsted, Donald W.; Durham, Katherine. Stability of Mental Health Attitudes: A Semantic Differential Study. Journal of Health and Social Behavior. 1976; 17:35-44. [PubMed: 1270784]

Page, Stewart; Day, D. Acceptance of the 'Mentally Ill' in Canadian Society: Reality and Illusion. Canadian Journal of Community Mental Health. 1990; 9:51-61.

Pescosolido, Bernice A.; Monahan, John; Link, Bruce G.; Stueve, Ann; Kikuzawa, Saeko. The Public's View of the Competence, Dangerousness, and Need for Legal Coercion of Persons with Mental Health Problems. American Journal of Public Health. 1999; 89:1339-45. [PubMed: 10474550]

Phelan, Jo C. Geneticization of Deviant Behavior and Consequences for Stigma: The Case of Mental Illness. Journal of Health and Social Behavior. 2005; 46:307-22. [PubMed: 16433278]

Phelan, Jo C.; Link, Bruce G. Fear of People with Mental Illnesses: The Role of Personal and Interpersonal Contact and Exposure to Threat or Harm. Journal of Health and Social Behavior. 2004; 45:68-80. [PubMed: 15179908]

Phelan, Jo C.; Link, Bruce G.; Stueve, Ann; Pescosolido, Bernice A. Public Conceptions of Mental Illness in 1950 and 1996: What Is Mental Illness and Is It To Be Feared? Journal of Health and Social Behavior. 2000; 41:188-207.

Premeaux, Sonya F. Impact of Applicant Disability on Selection: The Role of Disability Type, Physical Attractiveness, and Proximity. Journal of Business and Psychology. 2001; 16:291-98.

Ravaud, Jean-Francois; Madiot, Beatrice; Ville, Isabelle. Discrimination toward Disabled People Seeking Employment. Social Science and Medicine. 1992; 35:951-58. [PubMed: 1411702]

Reinke, Rebecca R.; Corrigan, Patrick W.; Leonhard, Christopher; Lundin, Robert K.; Kubiak, Mary Anne. Examining Two Aspects of Contact on the Stigma of Mental Illness. Journal of Social and Clinical Psychology. 2004; 23:377-89.

Ridgeway, Cecilia L. Linking Social Structure and Interpersonal Behavior: A Theoretical Perspective on Cultural Schemas and Social Relations. Social Psychology Quarterly. 2006; 69:5-16.

Ritsher, J Boyd; Phelan, Jo C. Internalized Stigma Predicts Erosion of Morale among Psychiatric Outpatients. Psychiatry Research. 2004; 129:257-65. [PubMed: 15661319]

Scheff, Thomas J. Being Mentally Ill: A Sociological Theory. Chicago: Aldine de Gruyter; 1966.

Schloss, Patrick J.; Soda, SL. Employer Attitudes Concerning Training Time and on the Job Success for the Mentally Handicapped in Low and High Unemployment Areas. Vocational Evaluation and Work Adjustment Bulletin. 1989; 22:129-32. 
Sibicky, Mark; Dovidio, John F. Stigma of Psychological Therapy: Stereotypes, Interpersonal Reactions, and the Self-Fulfilling Prophecy. Journal of Consulting and Clinical Psychology. 1986; 33:148-54.

Sirey, Jo Ann; Bruce, Martha L.; Alexopoulos, George S.; Perlick, Deborah A.; Friedman, Steven J.; Meyers, Barnett S. Stigma as a Barrier to Recovery: Perceived Stigma and Patient-Rated Severity of Illness as Predictors of Antidepressant Drug Adherence. Psychiatric Services. 2001; 52:161520. [PubMed: 11726752]

Snyder, Melvin L.; Kleck, Robert E.; Strenta, Angelo; Mentzer, Steven J. Avoidance of the Handicapped: An Attributional Ambiguity Analysis. Journal of Personality and Social Psychology. 1979; 37:2297-306. [PubMed: 160924]

Stone, Diane L.; Colella, Adrienne. A Model of Factors Affecting the Treatment of Disabled Individuals in Organizations. Academy of Management Review. 1996; 21:352-401.

Susman, Joan. Disability, Stigma, and Deviance. Social Science and Medicine. 1994; 38:15-22. [PubMed: 8146705]

Wagner, David G. The Labeling of Mental Illness as a Status Organizing Process. In: Lawler, EJ.; Markovsky, B., editors. Social Psychology of Groups: A Reader. Greenwich, CT: JAI Press; 1993. p. 51-68.

Webster, Murray, Jr; Hysom, Stuart J. Creating Status Characteristics. American Sociological Review. 1998; 63:351-78.

Westbrook, Mary T.; Legge, Varoe; Pennay, Mark. Attitudes towards Disabilities in a Multicultural Society. Social Science and Medicine. 1993; 36:615-23. [PubMed: 8456331]

Wright, Eric R.; Gronfein, William P.; Owens, Timothy J. Deinstitutionalization, Social Rejection, and the Self- Esteem of Former Mental Patients. Journal of Health and Social Behavior. 2000; 41:6890. [PubMed: 10750323]

\section{Biographies}

Jeffrey W. Lucas is associate professor of sociology at the University of Maryland. He operates a group processes experimental laboratory in which he and collaborators carry out research on power, status, influence, and leadership in groups.

Jo C. Phelan is professor of sociomedical sciences at Columbia University. Her research focuses on social inequalities in health and mortality; stigma, prejudice, and discrimination; and the impact of the genomic revolution on stigma and racial attitudes.

\section{APPENDIX}

\section{Computation of Expectation Values and Expected Resistance to Influence}

Status characteristics theory's formal version allows for precise calculations of expected $p(s)$ scores across conditions. The process begins with graphing the processes that lead from actors through status characteristics to performance expectations in each condition. In the following graphs, $\mathrm{P}$ refers to participants, $\mathrm{O}$ to partners, $\mathrm{D}$ to states of attributes we expect to act as diffuse status characteristics (educational attainment, mental illness, and physical disability), $\mathrm{C}$ to states of a specific status characteristic representing a high score on the first iteration of the group task, $\Gamma$ to general performance expectations, $C^{*}$ to the specific characteristic that participants believe is directly relevant to task success, and $\mathrm{T}$ to task success and task failure. 
Drawing from the formal version of status characteristics theory (see Berger et al. 1977) and procedures initially detailed in Fox and Moore (1979), we calculated the parameters $m=$. 506 and $\mathrm{q}=.129$ for our sample and determined the following expected $\mathrm{p}(\mathrm{s})$ scores:

Condition 1: .5060; Conditions 2 through 4: .5557; Condition 5: .3370; Conditions 6 through 8: .4267.

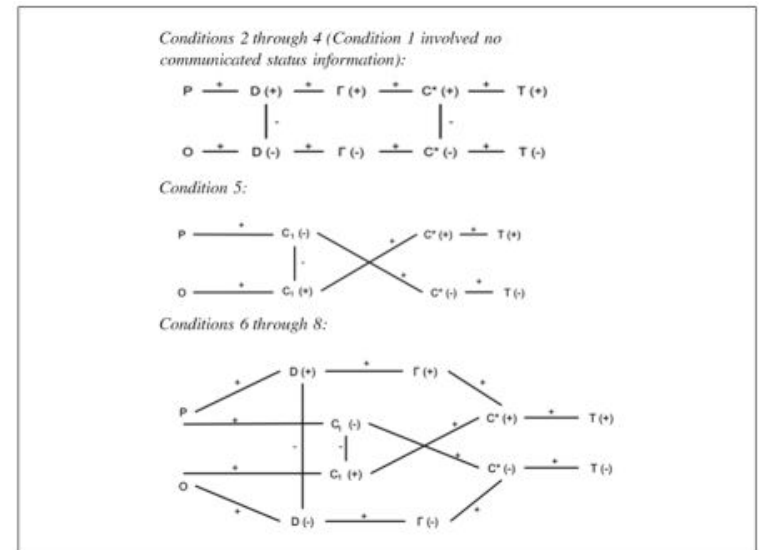




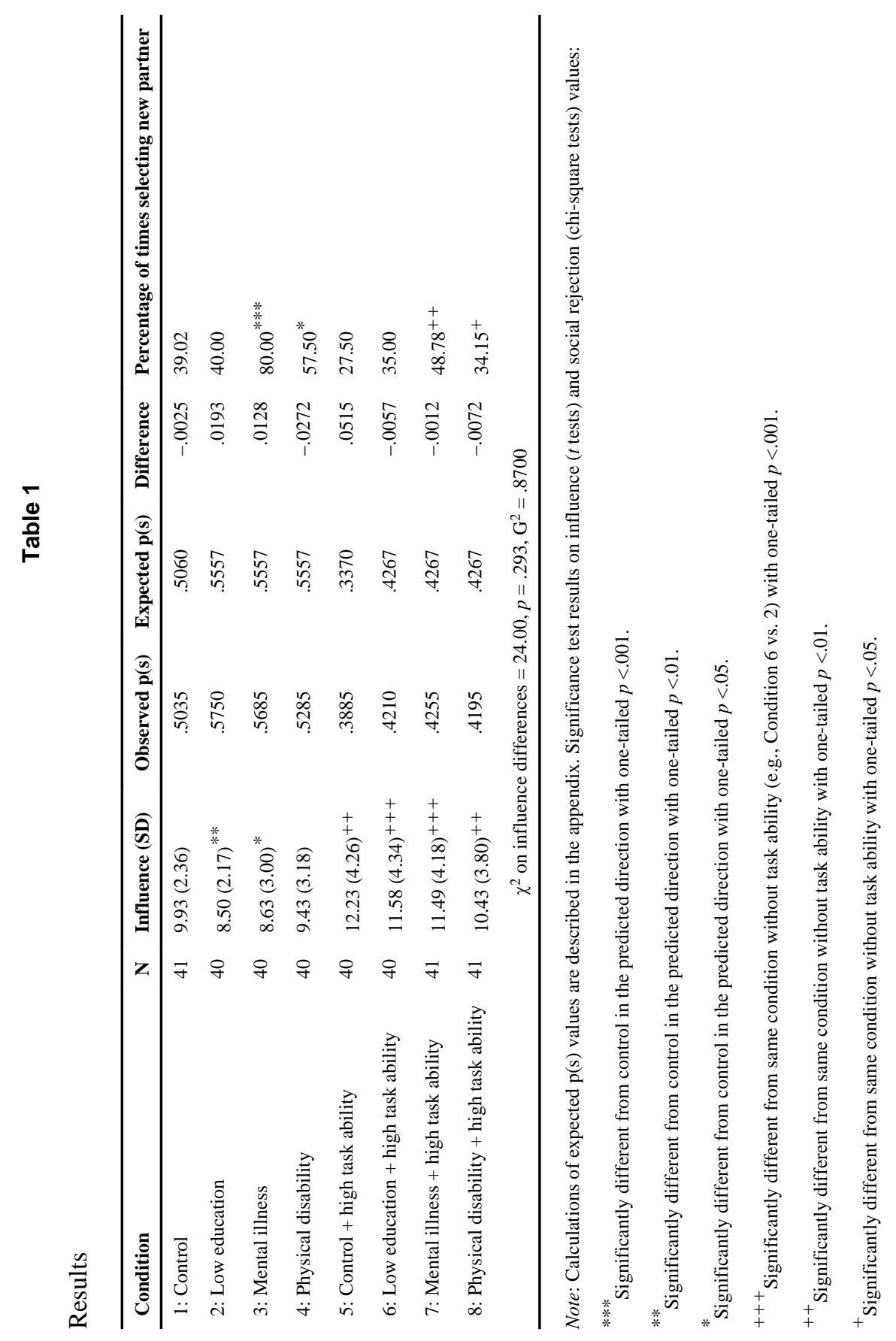

